\title{
NUMERICAL SCHLIEREN OF THE X-59 QUESST
}

Emily Williams, Yuenong Ling, Gonzalo Arranz, Adrián Lozano-Durán Massachusetts Institute of Technology

The X-59 QueSST (Quiet SuperSonic Technology) is a partnership project between NASA and Lockheed Martin with the primary objective of solving one of the most persisten challenges of supersonic flight: the sonic boom. This technology demonstrator will be flown over populated areas to provide data required to establish an acceptable commercial supersonic travel over land, expanding the global market for aircraft manufacturers developing supersonic passenger planes. The X-59 is intentionally shaped through tallored volume and lift distribution to separate the shocks and expansions associated with supersonic flight. The aircraft cruises at 55,000 feet at speeds up to Mach 1.4 . 